\title{
Reproductive biology of the monoecious clonal shrub Taxus canadensis ${ }^{1}$
}

\author{
Paul Wilson, ${ }^{2}$ Michelle Buonopane $^{3}$ and Taber D. Allison ${ }^{4}$ \\ ${ }^{2}$ Department of Biology, California State University, 18111 Nordhoff Street, \\ Northridge, CA 91330-8303 \\ ${ }^{3}$ Department of Biology, Bates College, Lewiston, ME 04240 \\ ${ }^{4}$ Department of Forestry and Wildlife, University of Massachusetts, Amherst, MA 01002
}

\begin{abstract}
Wilson, P. (Department of Biology, California State University, 18111 Nordhoff Street, Northridge, CA 91330-8303), M. Buonopane (Department of Biology, Bates College, Lewiston, ME 04240) And T. D. Allison (Department of Forestry and Wildlife, University of Massachusetts, Amherst, MA 01002). Reproductive biology of the monoecious clonal shrub Taxus canadensis. Bull. Torrcy Bot. Club 123: 7-15 1996. - Strobilus production, pollination, and maturation were studied in Taxus canadensis, a procumbent clonally-spreading shrub. Plants that produced many cones had greater shoot growth; no obvious tradeoff between sexual effort and vegetative growth was observed. T. canadensis is monoccious, but plants showed considerable variation in phenotypic gender. Bccause related species are dioecious, we hypothesize that $T$. canadensis cvolved from a dioecious ancestor. Monoecy may have been favored as a means of assuring pollination via selfing; the proportion of ovules pollinated was positively correlated with the number of male cones on a plant. Sclfing may be at the cost of inbrecding depression; $26 \%$ of the female cones aborted, about twice the percentage of the dioecious Taxus cuspidata. Application of nutrient fertilizer did not reduce the abortion percentage. Seed and aril maturation in $T$. canadensis occurred over a three month period, much more gradually than in $T$. cuspidata. Removal of the seeds, probably by antagonistic rodents, was very rapid and thorough in T. canadensis. Asynchronous ripening and monoecy may help reduce seed predation by rodents by reducing the conspicuousness of "fruiting" displays relative to the dioecious species.
\end{abstract}

Key words: monoecy, phenotypic gender, pollination limitation, reproductive allocation, sced abortion, seed consumption, Taxus canadensis.

Detailed studies of the reproductive biology of wind-pollinated woody plants have lagged behind those of showy meadow herbs. In the present study, on Taxus canadensis Marsh., we provide data relating to several topics that have received much attention from authors who were mainly focusing on other types of plants: (1) strategies of monoecy versus dioecy (Bawa 1980, 1994; Muenchow 1987; Thomson and Brunet 1990), (2) life history allocation to growth and reproduction (Delph 1990; Primack and Hall 1990; Cippollini and Whigham 1994), (3) ecological variation in the degree of pollination limitation (Zimmerman and Pyke 1988; Young and Young 1992; Wilson et al. 1994), (4) the abortion of immature seeds (Stephenson 1981; Willson and Burley 1983), and (5) seed predation versus effective seed dispersal (Janzen 1971; Price and Jenkins 1986). Taxus canaden-

\footnotetext{
' We thank S. Kinsman, B. Smith, J. Thomson, and B. Tomlinson for criticism, and the Hurwitzes of Petersham for permision to study their Taxus cuspidata trecs. Financial support was provided by the Mellon Foundation, the National Science Foundation, and the New England Consortium for Undergraduate Science Education. This work was done under the auspices of Harvard Forest.

Received for publication February 7, 1995 and in revised form July 1, 1995.
}

sis adds a distinct perspective on these issues, which we will speculatively relate to each other by outlining an integrated shift in the reproductive system of $T$. canadensis away from that of other Taxus species.

Taxus canadensis is a monoecious evergreen shrub native to mixed conifer-hardwood forests of the northeastern United States and southeastern Canada (Allison 1991). It is the only monoecious member of its genus, and monoecy in this case almost certainly arose from dioecy (see Discussion). Male and female cones are initiated during the summer in the axils of leaves, and they overwinter as buds. In the spring. ovules are fertilized by wind-dispersed pollen. Unpollinated ovules remain small and become whitishyellow, thus distinguishing them from developing nascent seeds. Throughout the summer some cones abort, with first the receptacle and then the seed coat becoming shriveled and yellow. The seed, receptacle, and pedicel of these aborted cones eventually fall off the plant. Mature female cones consist of a single seed surrounded by a fleshy red aril.

Taxus canadensis spreads clonally. Procumbent branches take root resulting in plants that expand horizontally. Branch by branch, the clone spreads along the forest floor, sometimes 
Table 1. List of study sites

\begin{tabular}{|c|c|c|c|c|c|}
\hline Site & $N^{a}$ & $\begin{array}{l}\text { Males } \\
\text { counted }\end{array}$ & $\begin{array}{l}\text { Females } \\
\text { counted }\end{array}$ & $\begin{array}{l}\text { Fertilizer } \\
\text { experiment }\end{array}$ & Site description \\
\hline Templeton & 51 & Yes & Yes & Yes & $\begin{array}{l}\text { Roadside, mixed hardwood-coni- } \\
\text { fer canopy, dense patch. }\end{array}$ \\
\hline Riceville Road & 72 & Yes & Yes & No & $\begin{array}{l}\text { On a steep hill, dense, next to } \\
\text { pasture, in a pine stand. }\end{array}$ \\
\hline Riceville Pond & 50 & No & Yes & No & $\begin{array}{l}\text { Open, relatively high light, road- } \\
\text { side, mixed canopy. }\end{array}$ \\
\hline Nelson Road & 44 & No & Yes & Yes $^{\mathrm{b}}$ & $\begin{array}{l}\text { On a hill, mixed hardwood-coni- } \\
\text { fer canopy. }\end{array}$ \\
\hline Nelson Brook & 50 & No & Yes & No & $\begin{array}{l}\text { Next to brook, moist, mixed } \\
\text { hardwood-conifer canopy. }\end{array}$ \\
\hline
\end{tabular}

"Number of "plants" sampled = rooted branches (see text).

${ }^{n}$ Possible effects on fruit maturation were not followed.

forming huge patches. In our study, a "plant" was considered to be one shoot system emanating from the forest litter. Our study plants were well spaced, but some of them may have been separate ramets of the same genet.

Taxus canadensis, though poisonous to humans, is a winter forage for deer and moose ( $\mathrm{Al}$ lison 1990a). Birds are assumed to act as dispersal vectors, eating the red aril and voiding the seed at some distance from the parent plant. Studies on other species of Taxus have shown that seeds fed to birds and spit out or excreted can later germinate (Barkowiak 1978). Not much information is available concerning seed predation by rodents, but Bartkowiak (1978) cites squirrels as eating Taxus seeds, and Allison (pers. obs.) has often noted rodent teeth marks and has observed chipmunks, squirrels, and mice eating Taxus canadensis seeds.

Methods. We studied Taxus canadensis at five sites in north-central Massachusetts, as described in Table 1. At each site, approximately fifty plants (i.e., rooted shoot systems) were chosen at random distances along parallel transects and tagged. In late May, we recorded for each plant the number of male cones, the number of female cones, and the number of withering, presumably unfertilized ovules, which we distinguished from pollinated immature seeds on the basis of color. Due to the late date of sampling, the counts of male cones are only estimatessome of the male cones may have already fallen off-and at three of the five sites the number of males cones could not be determined with satisfactory certainty (Table 1).

In late June, we collected data on size and growth for each plant at the five sites. The basal diameter at ground level was measured with cal- ipers twice, with the measurements taken perpendicular to each other. The mean of these two numbers was used to represent plant size. New (1994) growth was measured as the length of the five longest sprig tips, which were lighter green in color and softer in texture than previous years' growth. The average of these five numbers was used as an indication of the amount of growth.

Seed development was closely monitored on the twelve plants at the Templeton site that had ten or more ovules. To test for nutrient limitation of seed maturation, half the plants were given about one pint of Rapid Grow ${ }^{\circledR}$ fertilizer every two weeks from mid-June until the end of "fruiting" in September. At the beginning of July, we tagged each branchlet that bore a female cone, and we recorded the condition of the cone every two to three days. Cones were scored as (1) green and healthy but not yet with a red aril, (2) having a red aril, (3) removed leaving only the receptacle or pedicel stub, or (4) yellow and aborting. Very few were unaccounted for. For comparison, we also followed seed maturation and removal on a stand of cultivated Taxus cuspidata, which is a dioecous upright tree. The same procedure for marking and scoring female cones was used.

In order to evaluate whether or not rodents eat Taxus arils and seeds, we live-trapped a Peromyscus maniculatus underneath a clone of $T$. canadensis. This was done after the peak in seed maturation but while some seeds were still ripening. We placed the animal in a bucket with five mature $T$. canadensis cones and periodically observed what had been eaten.

Results. Gender. Phenotypic gender was calculated following Lloyd (1980; Lloyd and Bawa 

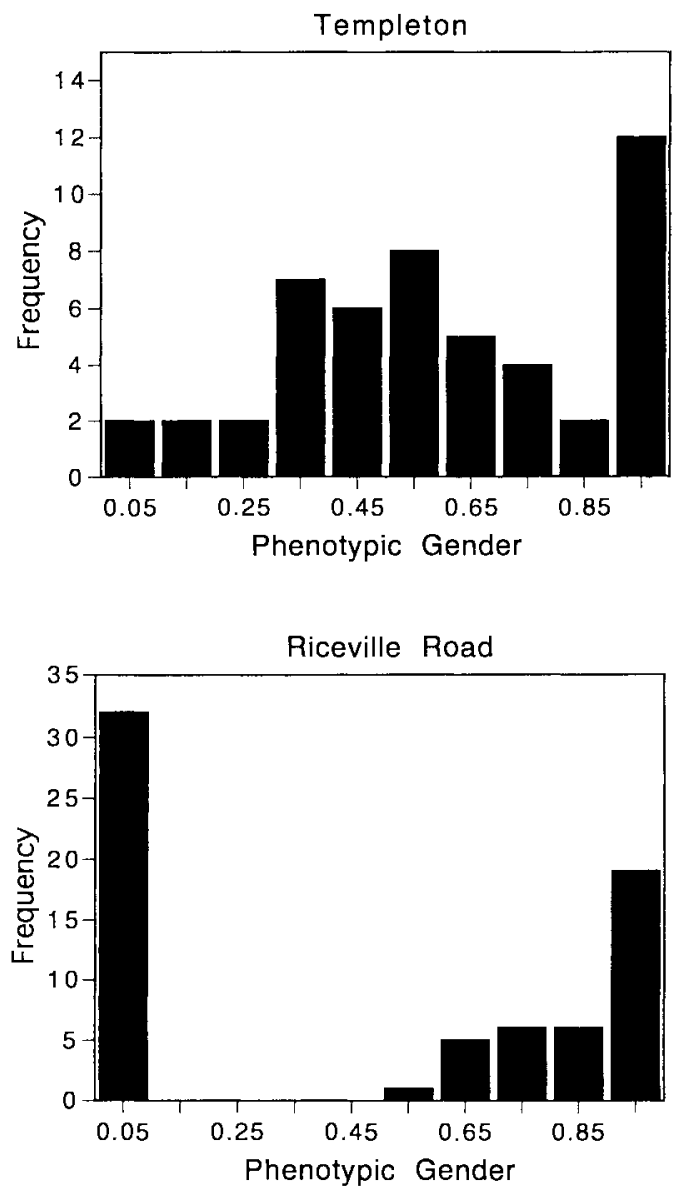

Fig. 1. Frequency distribution of phenotypic gender (sensu Lloyd and Bawa 1984) of Taxus canadensis for Templeton and Riceville Road. Gender ranges from 0.0 (female function) to 1.0 (male function).

1984; Allison 1991) as being the proportion of male to female cones relative to male and female representation in the rest of the population. An all-female plant would have a value of 0.0 , an all-male plant a value of 1.0. The distributions of phenotypic gender were tested for deviations from unimodality using a statistic proposed by Engleman and Hartigan (1969) and calculated for Taxus canadensis in northern Wisconsin by Allison (1991). Phenotypic gender at the Templeton site was not significantly different from unimodal $(P>0.05)$, but it did show considerable variation among plants, with a large number of hermaphrodites and some plants that were essentially all male (Fig. 1, upper panel). The Riceville Road site was significantly and distinctly bimodal $(P<0.05)$ with individuals strongly tending to be either male or female
(Fig. 1, lower panel). At both sites, intrapopulation differences are evident in the percentage of male and female plants. The two sites also differed in gender, with Templeton having a higher percentage of male plants and Riceville Road a higher percentage of female plants.

Growth AND Reproduction. We were interested in whether there was a negative (tradeoff) relationship, a positive (general vigor) relationship, or no consistent relationship between cone production and vegetative growth. In this and other analyses, the number of cones was squareroot transformed, since the square roots of cone numbers were more or less normally distributed. Furthermore, since larger plants naturally produce more cones than smaller plants, we attempted to remove the effect of size in two ways. First, we divided the number of cones (after transforming) by the basal diameter of the plant. In relating female reproductive output to growth, all five sites showed a weak but persis tent positive correlation (Fig. 2a, left panel). This relationship was significant for Riceville Road and marginally significant for Nelson Brook (see Fig. 2 for statistics). Plants that did not grow very much also did not produce many female cones; plants that grew more produced either few or many female cones, and those that produced few tended to be plants that were predominantly male (Fig. 2a). We also adjusted for basal diameter in a second type of analysis: we combined data from all the sites and calculated a partial correlation of the rank of female cone production against the rank of growth, holding basal diameter and population constant. In this analysis, $r=0.224(N=262 ; P<0.001)$. For the two sites where we scored male cone production, Templeton and Riceville Road, we looked for a correlation between male reproductive output and growth. We found positive correlations between growth and the square root of the number of male cones divided by basal diameter. This was significant for Templeton when all plants were included, and was significant for Riceville Road when only male plants were included (Fig. 2b, right panel).

Pollination Success. The percentage of female cones that developed after the receptivity stage, hereafter "pollination success," varied among populations. Templeton and Nelson Road had close to $100 \%$ pollination success while Riceville Road and Riceville Pond showed only $50-60 \%$ median pollination success. Nelson Brook had a median pollination success of $74 \%$ 


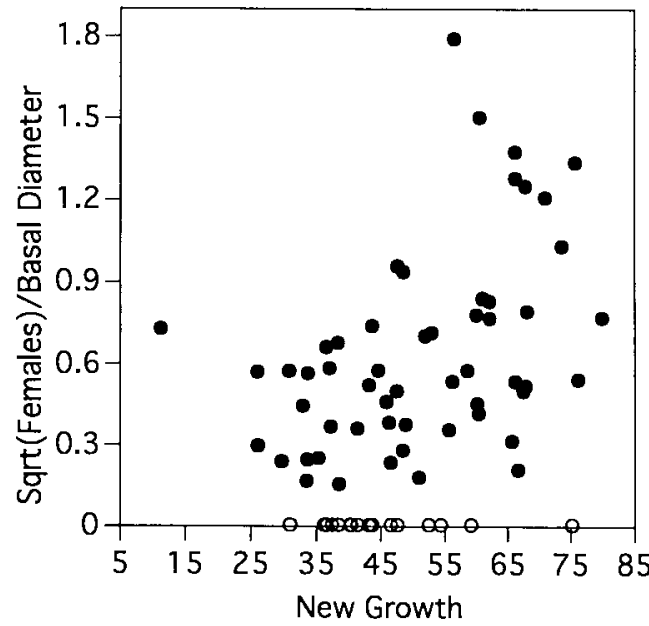

Riceville Road $r_{s}=0.42^{*}(n=55)$

Riceville Pond $r_{s}=0.13 \quad(n=50)$

Nelson Road $r_{s}=0.18 \quad(n=44)$

Nelson Brook $r_{s}=0.26^{\dagger}(n=49)$

Templeton $r_{s}=0.24 \quad(n=47)$

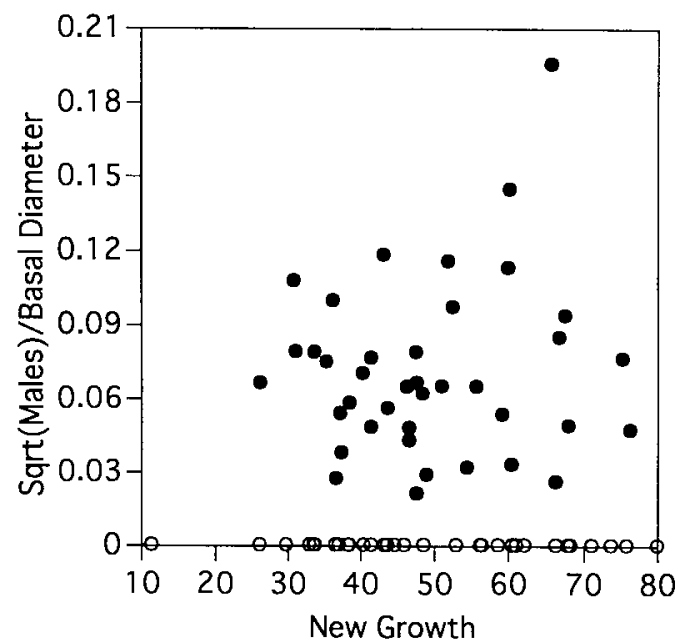

Riceville Road $r_{s}=0.059 \quad(n=72)$

males only $r_{s}=0.351^{*}(n=39)$

Templeton $r_{s}=0.345^{*}(n=47)$

Fig. 2. Comparison of reproductive output and growth for Taxus canadensis at Riceville Road. Sqrt $=$ Square root transformed. Spearman's Rank correlation coefficients are given for all five populations $(\uparrow P<0.1 ; * P<$ 0.05). Open circles indicate male individuals on the left panel and female individuals on the right panel.

(Table 2). The sites also differed in the amount of variation in pollination success among plants within each population. For example, Templeton showed little variation with most plants experiencing high pollination success. Riceville Road, however, displayed very broad variation, with a bimodal distribution of success. There were many plants with a pollination success of less than $5 \%$ and many with a pollination success close to $100 \%$, as well as variation between the extremes (Fig. 3). Pollination success was positively correlated with the number of male cones produced (Templeton and Riceville Road combined $\left.r_{\mathrm{s}}=0.57 ; N=93 ; P<0.001\right)$. A plant with a high number of male cones will have a high pollination success, but a plant with a low number of male cones might experience high or low pollination success (Fig. 4).

Seed Maturation, Abortion, and PredaTION. Aril and seed ripening was very gradual in Taxus canadensis (Fig. 5, upper panel). At the Templeton site, seed ripening extended over a period of three months. There was an early wave of maturation at the beginning of July, but maturation soon slowed, and the last aril did not turn red until the end of September. In addition to maturing gradually, the ripe "fruits" were spatially scattered within and among ramets and did not produce a showy display. The abortion rate was $26 \%$ overall; it ranged from $50 \%$ to $8 \%$, and there was no significant effect of nutrient fertil-

Table 2. Among-site variation in pollination success.

\begin{tabular}{lccc}
\hline & No. ovules pollinated & $\begin{array}{c}\text { Median } \\
\text { pollination success }\end{array}$ & $N^{d}$ \\
\hline Total no. of ovules & $423 / 44=94 \%$ & 1.0 & $(51)$ \\
Riceville Road & $324 / 1213=27 \%$ & 0.6 & $(72)$ \\
Riceville Pond & $341 / 572=60 \%$ & 0.5 & $(47)$ \\
Nelson Road & $6651 / 12=93 \%$ & 0.96 & $(37)$ \\
Nelson Brook & $175 / 235=75 \%$ & 0.74 & $(50)$ \\
\hline
\end{tabular}

\footnotetext{
${ }^{a}$ Kruskal-Wallis $\chi^{2}=45.13(4 \mathrm{df}) ; P<0.001$.

b Number of "plants" sampled = rooted branches (see text).
} 

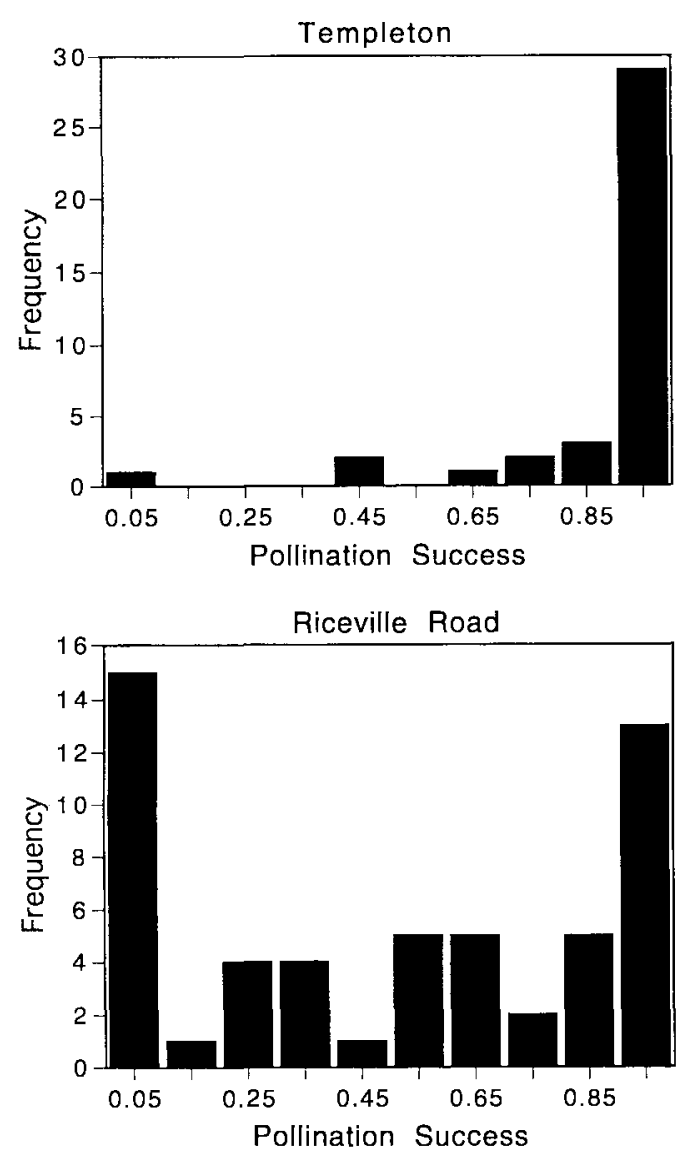

Fig. 3. Frequency distribution of pollination suc cess for Taxus canadensis for Templeton and Riccville Road.

izer addition on the proportion aborted (angularly transformed; $t=0.777$ with $10 \mathrm{df} ; P=$ 0.455 ). Most of the abortion happened well after the first arils of other seeds on a plant had turned red. In our study (unpubl. data) of the dioecious species Taxus cuspidata, maturation was much more simultaneous with most arils on a plant turning red in the period of a few days (Fig. 5, lower panel). Also the cones were produced in dramatic clusters on the trees. The abortion rate was lower, $13 \%$, and abortion occurred before the other cones matured-also most of this abortion occurred on one plant, unlike the situation in $T$. canadensis. Only three of the 189 cones that we followed were removed by animals. Most arils became mushy or rotten several weeks after becoming red, and then the cones fell to the ground. In Taxus canadensis when an aril turned red, the cone was generally removed very quickly by animals: the median time to re-

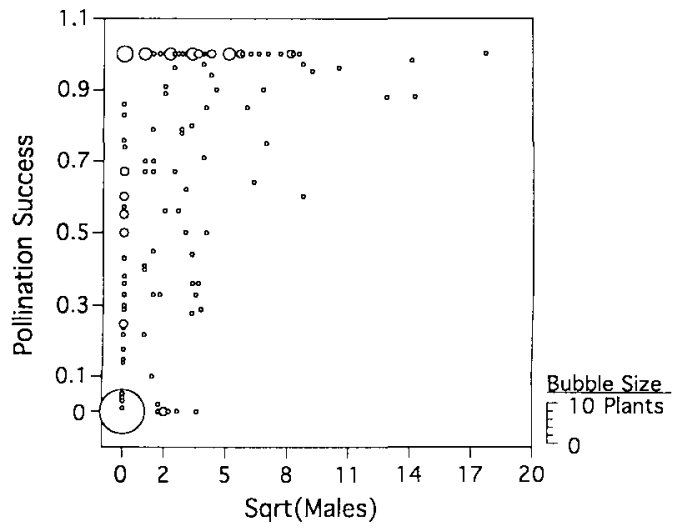

Fig. 4. Pollination success of femalc cones on abundance of male cones for Templeton and Riceville Road combined. Sqrt $=$ Square root transformed. Each bubble represents one to several plants, as indicated by size.
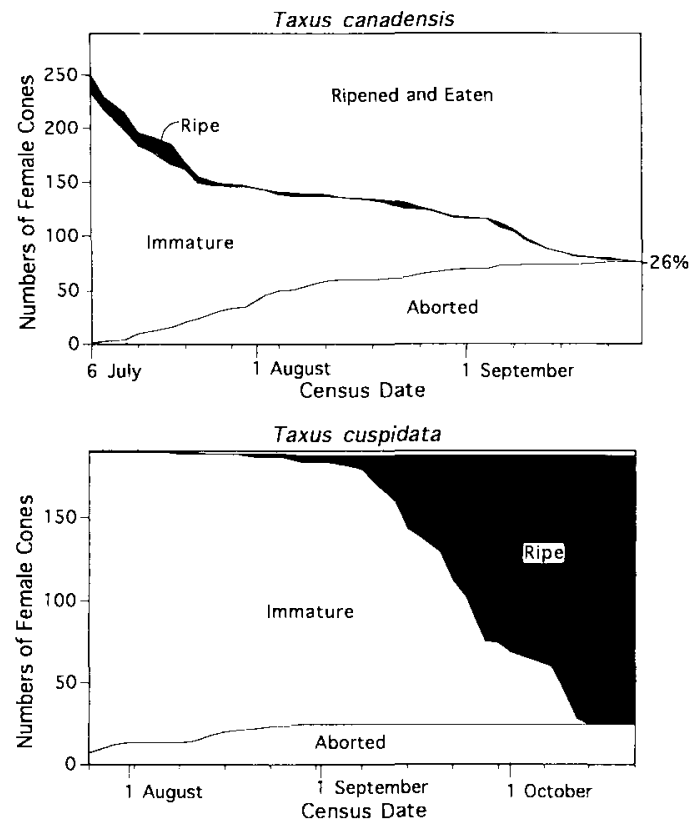

Fig. 5. Cumulative seed maturation and abortion. For Taxus canadensis, there were 13 cones that were eaten before they matured, and they are not included in the graphed data. "Ripe" means having an aril that was seen as having some red or in a few cases estimated as likely to turn red before the next census; it does not mean the arils and seeds had reached full size, which for $T$. canadensis most never did. All numbers on the graph are based on pooling all censused plants in the population, but there were not major differences among plants in $T$. canadensis. For Taxus cuspidata, the several declines in number of immature cones are a result of different individuals maturing their cones on different weeks; even when these individuals are pooled the simultaneous maturation is dramatic compared to T. canadensis. 
moval was 2.3 days (one census unit), the mean $3.8 \pm 2.72 \mathrm{SD}(N=74)$. Fifty-one percent of cones were removed when they had been green in the previous census ( $N=184)$. These typically were well developed, and some of them may have been removed after turning red but before we recorded them as such. We could not tell directly whether cones were being removed by birds that might disperse the seed or by rodents, but in numerous instances we found gouged arils with the seed removed and pedicel stubs that seemed to have been cut by a sharp tooth, not broken by merely having the aril plucked. Our captive deer mouse ate all five cones that we provided, leaving only the intact receptacles. The first was eaten after 1 hour and 22 minutes, and when we left the mouse alone and returned some 4 hours later, the remaining four cones were eaten, again with the receptacles left intact.

Discussion. Our results on gender distribution confirm the findings of Allison (1991) from sites in the Apostle Islands of Lake Superior. In both regions, and hence probably for the species a whole, there is a dioecious tendency toward bimodal gender. This tendency may be a phylogenetic holdover from a dioecious ancestry. All other species of Taxus seem to be usually dioecious ( $T$. baccata and $T$. cus pidata-pers. obs.; T. brevifolia-Taylor and Taylor 1981; T. floridana-Godfrey 1988; $T$. globosa-Standley and Steyermark 1958; $T$. sumatrana-de Laubenfels 1978; T. chinensis, $T$. wallichiana, and $T$. yunnanensis-Botanical Institution Chinese Academy of Sciences, Bejing, 1972, and Cheng et al. 1978). Furthermore, related genera are dioecious such that a phy logenetic analysis of character evolution unambiguously infers the three hypothetical common ancestors below Taxus to have been dioecious (Hart 1987; Donoghue 1989). It is, therefore, almost certain that Taxus canadensis is secondarily monoecious.

What ecological conditions might be functionally associated with the change in breeding system toward monoecy? Most discussions of the strategic stability of monoecy versus dioecy have focused on evolution in the opposite direction, that is, from cosexuality to dioecy. For in stance, the arguments presented by Bawa (1980), Givnish (1980), Muenchow (1986), and Charlesworth and Charlesworth (1978) all center on possible reasons for the sexes becoming separated. The arguments, however, can be turned around. Two non-mutually exclusive theories seem reasonable for Taxus canadensis: (1) monoecy may have been favored because it allowed for self-pollination in plants that had become frequently pollen limited (Allison 1990b); and (2) dioecy may have been no longer favored because the ecology of seed disperseral and survival no longer made it advantageous to have as many "fruits" as possible concentrated on half the plants (Bawa 1980; Givnish 1980). Both chronic pollen limitation and chronic seed predation may in turn be due to the prostrate, outwardly spreading, clonal habit.

Life history theory typically assumes that there is a tradeoff between reproductive effort and vegetative growth (Willson 1983; Stearns 1992; Reekie and Bazzaz 1992). Our results do not support this assumption. We found positive correlations between cone production and the length of new shoots, even holding plant size constant. This could be accounted for by a number of mechanisms (Reekie and Bazzaz 1987). There seems to be more variance in general vigor affecting both growth and reproduction than in any tradeoff between growth and reproduction. Of course, there may still be a negative genetic or evolutionary correlation, but most of the variance among plants seems to be in how much resource they have acquired, not in how they allocate it (van Noordwijk and de Jong 1986). This suggests that the plants that are best at spreading clonally may also be those that are best able to afford producing large numbers of male and female cones. Such a complex positive correlation cannot be proven without a controlled experiment, but the census data do point in that direction. The plants that grew more, and probably have spread out more, also produced more cones and probably sired and set more seed.

Our pollination-success results indicate that some of our populations were experiencing pollen limitation (see also Allison 1990b, 1990c, 1993), but, interestingly, some parts of those populations showed high pollination success Considerable variation must therefore exist in the availability of airborne pollen at a very local scale. Substantial site-to-site differences in pollination limitation have been found in insect and bird pollinated species (see references in Wilson et al. 1994, p. 285; Wilson 1995). Our results provide an example of such variation in a species with wind dispersed pollen. Some of this variation among sites may be explained by variation in levels of selfing associated with the 
degree of monoecy. As the number of male cones increased pollination success also increased. Selfing may have prevented pollen limitation in some plants and in some sites. Specifically, pollination did not limit female function at Templeton where plants were mostly hermaphrodites or males, whereas pollination was limiting for some plants at Riceville Road where there were large numbers of essentially female plants. It is quite possible that, if Taxus canadensis were still dioecious, it would be chronically pollen limited. The architecture of the species seems to act against adequate cross-pollination: layering increases the size of clones horizontally rather than vertically, and plants are very close to the ground as well as protected by a dense overstory such that pollen grains may not have far to fall in air that is rarely turbulent. Individuals that were able to become cosexual may have been favored after the evolution of this growth form.

The high rates of seed abortion that exist in many plants are a curious feature to explain (Stephenson 1981). Several explanations have been proposed. Conceivably it is because plants are hedging their bets in favor of stupendously good years when resources are so plentiful that they are able to mature all their seeds (Ehrlén 1993). Or perhaps it is because mother plants are choosing to mature the best embryos from a larger field of candidates (Casper 1988; Bertin and Peters 1992). Or perhaps some embryos are genetically inviable on their own, either because of inbreeding or genetic bad luck (Lee 1988). Seed abortion in Taxus canadensis was $26 \%$ at our study site in Massachusetts, and this confirms the high levels of abortion observed by Allison (unpubl. data) in Minnesota and Wisconsin. Almost all of the abortion happened after many of the cones that would develop had already completely matured. Light limitation may play a role. Aborted cones are a bit smaller than fully mature cones-the seed is perhaps half as large, and there is no aril. Still it is hard to believe that not maturing them is energetically imposed. In addition, we found no evidence from our nutrient fertilizer study that abortion was due to lack of mineral nutrients. The explanation that seems the most reasonable and would be related to differences between the species in mating system is seed failure due to selfing. Allison (1990c) did an experiment showing that female cones on emasculated plants (where selfing was prevented) has similar abortion rates to monoecious plants (where pollination success was higher presumably because of selfing; see also Allison 1993). His experiment did not test whether or not there is inbreeding depression given equal pollination by self and outcross pollen. Monoecy may yet be shown to be at the cost of increased abortion due to inbreeding depression.

Seed predation was exceedingly high in our study of Taxus canadensis. Although we have not discovered a way of directly distinguishing between removal of seeds by birds versus rodents, we believe rodent attack was overwhelming, as is quite possibly the case for many understory plants (Heithaus 1981). Because $T$. canadensis plants are procumbent, the cones are produced close to the ground where they are easily accessible to mice and chipmunks. We found dozens of instances of what we interpreted as teeth marks. And we know that rodents will eat seeds and arils of $T$. canadensis. Some seeds are even eaten before they mature, and most do not stay on the plant for more than a few days after developing a red aril. It would be interesting to do an experimental study of how distance from the ground and number of ripe cones affect removal rates by rodents and birds. There is no indication that large "fruit" crops would be especially attractive to birds who might disperse the seeds. There is no indication that birds are attracted to the seeds of $T$. canadensis at all. Thus, Givnish's $(1980,1982)$ theory for the evolution of dioecy could work in reverse for the evolution of monoecy in $T$. canadensis: allocating energy to male function probably does not lower the fruit crop below any threshold of attractiveness to beneficial birds but it might to antagonistic mammals (on the quality of mammals as seed dispersers/predators see Smith et al. 1986; Davidar and Morton 1986; Carr 1992). The very gradual and scattered presentation of "fruit" much more gradual and scattered than in Taxus cuspidata-might well reflect an ecology in which a lone cone has a greater chance of not being eaten than a cone on a heavily laden plant, in which case the female gain curve would be convex, not concave, and monoecy would be favored (Charnov 1982).

\section{Literature Cited}

Alluson, T. 1990a. The influence of deer browsing on the reproductive biology of Canada yew (Taxus canadensis Marsh.). I. Direct effect on pollen, ovule, and seed production. Oecologia 83: 523 529. 
1990b. Pollen production and plant density affect pollination and seed production in Taxus canadensis. Ecology 71: 516-522

1990c. The influence of deer browsing on the reproductive biology of Canada yew (Taxus canadensis Marsh.). II. Pollen limitation: An indirect effect. Oecologia 83: 530-534.

-. 1991. Variation in sex expression in Canada yew (Taxus canadensis). Am. J. Bot. 78: 569-578 - 1992. The influence of deer browsing on the reproductive biology of Canada yew (Taxus canadensis Marsh.). III. Sex expression. Oecologia 89: 223-228

- 1993. Self-fertility in Canada yew (Taxus canadensis Marsh.). Bull. Torrey Bot. Club 120: $115-120$

BARTKOWIAK, S. 1978. Seed dispersal by birds. In S. Bialobok [ed.], The Yew-Taxus baccata L. Foreign Scientific Publications Department of the National Center for Scientific, Technical and Economic Information, Warsaw, Poland

BAWA, K. S. 1980. Evolution of dioecy in flowering plants. Annu. Rev. Ecol. Syst. 11: 15-40.

1994. Pollinators of tropical dioecious angio sperms: A reassessment? No, not yet. Am. J. Bot 81: 456-460.

Bertin, R. I. And P. J. Peters. 1992. Paternal effects on offspring quality in Campsis radicans. Am. Nat. 140: $166-178$.

Botanical Institution, Chinese Academy of SCI ENCES, BEJING. 1972. Iconographia cormophytorum Sinicorum, Vol. 1.

CASPFR, B. B. 1988. Evidence for selective embryo abortion in Cryptantha flava. Am. Nat. 132: 318 326.

CARR, D. E. 1992. The relationship between crop size and fruit removal and its implication for the evolution of dioecy. Can. J. Bot. 70: 1784-1789

Cimari.fsworth, D. and B. Charlesworth. 1978. A model for the evolution of diocey and gynodioecy. Am. Nat. 112: 975-997.

Cinarnov, E. L. 1982. The theory of sex allocation. Princeton University Press, Princeton, New Jersey.

Cheng, W.-C., L.-K. FU AND C.-D. CHU. 1978. Taxus, pp. 438-448. In. Flora Republicae Popularis Sinicae, Vol. 7

Cippollini, M. L. and D. F. Whigham. 1994. Sexual dimorphism and cost of reproduction in the dioe cious shrub Lindera benzoin (Lauraceae). Am. J. Bot. 81: 65-75.

Davidar, P. ANd E. S. Morton. 1986. The relation ship between fruit crop sizes and fruit removal rates by birds. Ecology 67: 262-265.

DF I ALBENFFISS, D. J. 1978. The taxonomy of Phi1 ippine Coniferae and Taxaceae. Kalikasan 7: 117152.

DELPH, I. F. 1990. Sex-differential resource allocation patterns in the subdioecious shrub Hebe subalpina. Ecology 71: 1342-1351.

Donoghle, M. J. 1989. Phylogenies and the analysis of evolutionary sequences, with examples from seed plants. Evolution 43: 1 137-1 156

EIIRIÉN, J. 1993. Ultimate functions of non-fruiting flowers in Lathyrus vernus. Oikos 68: 45-52.

Engleman, L. ANd J. A. Hartigan. 1969. Percentage points of the test for clusters. J. Am. Statistical Assoc. 64: $1647-1648$
Givnish, T. J. 1980. Ecological constraints in the evolution of breeding systems in seedplants: dioecy and dispersal in gymnosperms. Evolution 34: 959972 .

. 1982. Outerossing versus ecological constraints in the evolution of dioecy. Am. Nat. 119 849-865.

GodfrFy, R. K. 1988 . Trees, shrubs and woody vines of northern Florida and adjacent Georgia and Alabama. University of Georgia Press, Athens, Georgia.

HART, J. A. 1987. A cladistic analysis of conifers preliminary results. J. Arnold Arb. 68: 269-307

Heithals, E. R. 1981. Seed predation by rodents on thrce ant-dispersed plants. Ecology 62: 136-145.

JANZEN, D. H. 1971. Secd predation by animals. Annu. Rev. Ecol. Syst. 2: 465-492.

LeE, T. D. 1988. Patterns of fruit and seed production pp. 179-202. In J. Lovett Doust and L. Lovett Doust [eds.], Plant reproductive ecology. Oxford University Press, New York.

LlOYD, D. 1980. Sexual strategies in plants. III. A quantitative method for describing the gender of plants. New Zeal. J. Bot. 18: 103-108.

LLOYD, D. G. AND K. S. BAWA. 1984. Modification of the gender of seed plants in varying conditions. Evol. Biol. 17: 255-338.

MLEnCHOW, G. E. 1987. Is dioecy associated with fleshy fruit? Am. J. Bot. 74: 287-293.

PrICE, M. V. AND S. H. JENKINS. 1986. Rodents as seed consumers and dispersers, pp. 191-235. In D. R Murray [ed.], Seed dispersal. Academic Press, New York.

Primack, R. B. anid P. Halli. 1990. Costs of repro duction in the pink lady's slipper: A four-year experimental study. Am. Nat. 136: 638-656

REFKIE, E. G. AND F. A. BAZZA\%. 1987. Reproductive effort in plants. 3. Effects of reproduction on vegetative activity. Am. Nat. 129: 907-919.

AND —. 1992. Cost of reproduction as reduced growth in genotypes of two congeneric species with contrasting life histories. Oecologia 90: $21-26$

Smith, B. H., M. L. Ronsheim and K. R. Swart/. 1986. Reproductive ecology of Jeffersonia diph $\%$ la (Berberidaccae). Am. J. Bot. 73: 1416-1426.

Standley, P. C. And J. A. Steyermark. 1958. Flora of Guatemala. Fieldiana 24: 60-62.

Stearns, S. C. 1992. The evolution of life histories. Oxford University Press, Oxford.

Stephenson, A. G. 1981. Flower and fruit abortion: Proximate causes and ultimate functions. Annu. Rev. Ecol. Syst. 12: 253-279.

TAYLOR, R. L. AND S. TAYLOR. 1981. Taxus brevifolia in British Columbia. Davidsonia 12: 89-94.

THOMson, J. D. AND J. BRLnET. 1990. Hypotheses for the evolution of dioecy in seed plants. Trends Ecol. Evol. 5: 11-16.

VAN NoOrdwiJk, A. J. ANI) G. DF JONG. 1986. Acqui sition and allocation of resources: Their influence on variation in life history tactics. Am. Nat. 128: $137-142$

WiLlson, M. F. 1983. Plant reproductive biology. Wiley, New York

AND N. BLrley. 1983. Mate choice in plants. Princeton University Press, Princeton, New Jersey. WILSON, P. 1995. Variation in the intensity of polli- 
nation in Drosera tracyi: Selection is strongest when resources are intermediate. Evol. Ecol. 9: 1-15. , J. D. Thomson, M. L. STANTON AND L. P. Rig NEY. 1994. Beyond floral Batemania: gender biases in selection for pollination success. Am. Nat. 143: $283-296$.
Yolng, H. J. AND T. P. YounG. 1992. Alternative outcomes of natural and experimental high pollen loads. Ecology 73: 639-647.

Zimmerman, M. ani G. H. Pyke. 1988. Reproduction in Polemonium: Assessing the factors limiting seed set. Am. Nat. 131: 723-738. 